\title{
Using Photovoice as Methodology, Pedagogy and Assessment Tool in Education: Graduate Students' Experiences and Reflections
}

\author{
Ting WANG \\ Faculty of Education, University of Canberra, Australia \\ Faculty of Education, Beijing Normal University, Beijing, P.R. China \\ Ting.Wang@canberra.edu.au
}

\begin{abstract}
Participatory visual methods are increasingly used in various disciplines. This article focuses on using photovoice as a methodology, pedagogy and participatory assessment tool in education through Chinese graduate students' experiences with a photovoice project. The study investigated the efficacy of photovoice as a pedagogical and assessment tool, and the utility of photovoice as a participatory visual research method to examine impacts of globalization on China. A group of sixty Chinese students who studied an Australian transnational Master of Education program participated in this photovoice project. Analysis of the participants' photographs, narratives, and reflections provided evidence that photovoice can be employed as an effective pedagogical and assessment tool. The findings showed that photovoice related learning was emancipatory and transformative. Photovoice offered opportunities for the participants to deepen understanding and enhance critical consciousness. The study suggests that photovoice as a participatory research methodology has educational and cultural appropriateness for Chinese students.
\end{abstract}

\section{Keywords}

photovoice - visual research methods - participatory research methods - assessment tool - pedagogy - qualitative research 
Visual data are everywhere. Visual methods are accepted tools for qualitative research. The proliferation of visual methods in various landscapes and disciplines over the past two decades provides alternative ways of conducting qualitative research (Pain, 2012). Photovoice is an approach that incorporates photography with participatory action (Wang, 2003; Wang \& Burris, 1994; Wang \& Burris, 1997). Photovoice was originally developed as a participatory action research method in which individuals photograph their everyday health and work realities. The photovoice process presents a distinctive way to understand individual perceptions of an issue. It is also structured as a mechanism that engages participants in group discussion about their images and to present the images in public forums (Wang \& Redwood-Jones, 2001). This form of qualitative research has proved valuable and effective across disciplines and settings since its inception in 199os. It is predominantly used in participatory action research, community-based participatory research, and qualitative methodologies, such as ethnography, visual narrative inquiry and case studies (Simmonds, Roux, \& Avest, 2015).

Photovoice as a participatory visual research method has been used widely in the areas of health, community development, management, social research, and education (Bennett et al., 2019; Komaie, Gilbert, Arroyo, \& Goodman, 2018; McIntyre, 2003; Wang, Morrel-Samuels, Hutchison, Bell, \& Pestronk, 2004; Wang, Wu, Zhan, \& Carovano, 1998; Warren, 2005; Wilson et al., 2007). Despite a growing interest in using photovoice as a pedagogical tool (Chio \& Fandit, 2007; Hernandez, Shabazian, \& McGrath, 2014; Komaie et al., 2018; Latz, PhelpsWard, Royer \& Peters, 2016), there is a paucity of research on using photovoice as a methodology, pedagogy, and assessment tool in Chinese education contexts.

There is a dearth of research on using photovoice as methodology and pedagogy with Chinese graduate students. This study intended to address the gaps and contribute to the photovoice literature. It also intended to determine the efficacy of photovoice as an innovative research method examining the impacts of globalization on Chinese society, culture, education, and training. Globalization has drawn increasing attention from scholars, but limited research has been conducted to employ the photovoice method to investigate this issue from multiple perspectives of Chinese graduate students.

The research aimed to help participants gain a critical understanding of their lived experiences with globalization, while providing an opportunity for them to have a hands-on experience of using photovoice as a nonconventional qualitative research method and to transfer what they learned 
into practice. This study explored whether looking at globalization from their own perspectives could translate into a greater sense of empowerment and critical awareness in their lives and workplaces. The photovoice project offered an alternative approach to assessment, which was innovative, culturally relevant and context specific.

\section{2 \\ Literature Review}

\subsection{Visual Research}

Perception is a progressing psychological concept which is pre-formed before PSTs enters preparation programs (Rushton, 2004), and is socially constructed with meaning created within their social context (Erlandson, 2014; Lortie, 1975; Merleau-Ponty, 2002). This implies that perception is no easy task for TPPS (Caprano, Capraro, Capraro, \& Helfeldt, 2010; Schaffer et al., 2014). т P Ps needs to provide PSTs various pedagogical approaches and educational experiences that have the power to change their stereotypical perspectives on teaching profession (Wright et al., 2019), since their perceptions have valuable and lasting impact not only on themselves, but also on students that they are prepared to service (Khalid et al., 2017).

\subsection{Photovoice as a Participatory Methodology}

Developed in mid-199os by Caroline Wang and Mary Ann Burris, photovoice was first used to empower the silenced rural women in Yunnan Province, China to influence the policies and programs affecting them (Wang, 1999). Since that endeavour, a series of photovoice projects have been documented in the literature, and the approach has been used effectively in different settings and with diverse populations (e.g. Baker \& Wang, 2006; Killion \& Wang, 1999; Kroeger et al., 2004; Strack \& Magill, 2004; Wang et al., 2004; Wang \& Pies, 2004; Wang et al., 1998; Wang, Yuan, \& Feng, 1996; Wilson et al., 2007). Researchers employing photovoice have demonstrated the utility of group discussion among homeless people (Dixon \& Hadjialexiou, 2005; Wang, Cash, \& Powers, 2000), lower income urban youth (Wang et al., 2004), older U.S. women living with HIV/AIDS (Gosselink \& Myllykangas, 2007), Canadian indigenous women's experience with cancer (Thomas et al., 2015), marginalized people in a rural town in South Africa (Harley, 2012). Photovoice has a potential to empower participants by giving voice to traditionally stigmatized, marginalized, and discriminated groups (Palys \& Atchison, 2012; Thomas et al., 2015). Moreover, "photovoice can yield fascinating empirical data and provide unique insights 
into diverse phenomena, as well as empowering and emancipating participants by making their experiences visible" (Oliffe \& Bottorff, 2007, p. 850).

Photovoice is a vital tool for Community-Based Participatory Research. It actively encourages participants to use the photographs to depict their perceptions and share their perspectives on community life, through either written or spoken narratives about the significance of their pictures. Photovoice blends a grassroots approach to photography and social action. It provides a process by which people can "identify, represent, and enhance their community through a specific photographic technique" (Wang \& Burris, 1997, p. 369). Photovoice projects have been conducted with a variety of populations to empower participants to explore and communicate important messages about their lives and communities (Bender, Harbour, Thorp, \& Morris, 2001; Berman, Ford-Bilboe, Moutrey, \& Cekic, 2001; Gallo, 2002; LeClerc, Wells, Craig, \& Wilson, 2002).

The photovoice methodology rests upon three theoretical underpinnings: (a) Freire's $(1970,1973)$ theory of critical consciousness, (b) feminism and notions of voice, and (c) participatory documentary photography (Wang et al., 2004). This theoretical approach allows individuals from various social and economic status to use the photovoice method to address their needs and concerns through a powerful means: the visual image (Wang \& Burris, 1997). Freire (1970) noted that the process of creating visual images is often a source of empowerment, as are group dialogues that affirm individuals' collective struggles and insights (Fournier, Mill, Kipp, \& Walusimbi, 2007; Wallerstein \& Bernstein, 1988).

Photovoice is an innovative participatory tool which helps people to use visual evidence to recognize and voice their problems and potential solutions to policy makers (Wang \& Burris, 1997). The process begins with participants photographing personally relevant objects, items, or activities around a specific topic or issue. Once the photographs are developed, each participant chooses a subset of pictures to share. The participants come to a series of scheduled meetings to engage in dialogue about their photographs. Group interactions address the relation of each picture to the designated theme, the issues depicted in the photograph, and the relevance of those pictures to stakeholders' lives (Carnahan, 2006).

Photovoice has gained popularity as a participatory qualitative research method that permits researchers from various disciplines to visualize individuals' perceptions about their everyday realities. It is designed to specifically tap into daily realities and the core meanings and significances of these realities as defined by research participants themselves (Fournier et al., 2007; Harrison, 2002; McIntyre, 2003; Nowell, Berkowitz, Deacon, \& Foster-Fisherman, 2006; 
Wang \& Burris, 1997). The photographic component of photovoice provides additional information not available in traditional qualitative approaches such as interviews and focus groups. Photographs aid the researcher by providing a window into the subjectivity of participants' reflections. The process of discussing the content of photographic imagery allows participants to both share and guide researchers through an external view of the participants' internal realities (Collier, 1979; Nowell et al., 2006).

\subsection{Photovoice as a Pedagogical Tool and Its Potential as an Assessment Tool}

While photovoice is predominantly a research methodology, some scholars have explored its pedagogical applications (Latz et al., 2016). For instance, Gallo's (2002) research investigated the ways in which English as a Second Language learners used photography in a learner centered workplace literacy program to solve problems and facilitate language learning. Mueller (2006) explored the perceptions of Canadian teachers through using photovoice to see how one might better prepare and support them in their efforts to teach their Inuit students. Carnahan (2006) described how photovoice led to improved engagement with peers and learning materials for two young boys with autism, and how teachers used photovoice to articulate their strengths and needs related to teaching students with autism and other disabilities. Chio and Fandit (2007) explored pedagogical and teaching possibilities offered by photovoice and provided a response to calls for more self-reflective and inclusive pedagogy. Extrapolating photovoice to the context of the diversity classroom, they discussed how the methodology can aid management educators in developing approaches and activities that foster greater participatory engagement between students and subject matter, knowledge, and learning. They argued that educators can adopt or adapt the photovoice for their own use.

In recent years, photovoice has been used as a pedagogical tool to examine the parallel learning processes of college students and preschool children through service learning (Hernandez et al., 2014), to introduce qualitative research methods to community members and increase their research literacy (Komaie et al., 2018). Latz et al's (2016) study explored a course-based photovoice project on a graduate and community college student collaboration. Their work provides evidence of the power of photovoice - employed as student-led participatory action research - as a research approach, pedagogical tool, and partnership-building device. Ciolan and Manasia's (2017) study suggests that photovoice can be enriching for studying the ways students engage in learning activities and support authentic conversations about how learning takes place and what students are thinking about this process. In photovoice, the 
"imaginative process" often includes facilitated activities that support the photovoice steps. These pedagogical elements are adapted to particular settings, research projects and influence the crafting of participant-produced images (Switzer, 2019). Despite a dearth of empirical studies which explicitly focused on using photovoice as an assessment tool, the existing literature suggests a potential role of photovoice as a useful assessment tool in education.

\subsection{Challenges for Photovoice}

Photovoice projects have been conducted with a variety of cultures and population groups to explore a range of issues in education and beyond (Latz, 2017). There is an increasing interest in essentials of photovoice in participatory visual research (Harper, 2019). Despite numerous benefits it can provide for all stakeholders involved in the project (i.e., participants, researchers, the broader community, and decision-makers), there are methodological and ethical challenges. The process is very time consuming and requires a large investment of both human and financial resources (Nykiforuk, Vallianatos \& Nieuwendyk, 2011).

Photovoice is often described as accessible to vulnerable or marginalized groups and culturally appropriate for research with indigenous peoples (Bennett et al., 2019). Along this popularity is a growing concern regarding rigor in visual method's application, such as its misuse as a "quick-and-easy" replacement for long-term ethnographic engagement in fieldwork contexts (Gubrium \& Harper, 2013). There are limited "how-to" guides and researchers who engage in photovoice research often implement traditional qualitative methods for analyzing their data. Some researchers merge creativity with rigor to illustrate alternative means to analyze photovoice research data (Capous-Desyllas \& Bromfield, 2018). One of the intensions of the photovoice method is to attempt to overcome the power imbalance between the researcher and participants, but only to a certain extent. An imbalance of power between them is present even in this form of participatory model.

There are potential ethical threats to conducting and disseminating visual research, such as consent issues, data anonymity, confidentiality, and visual data use and distribution (Hannes \& Parylo, 2014). Cameras create a distance between the viewer and what is being viewed. The fate of visual products has been given very little attention. Can photographs ever really be a true reflection of reality? Once in the public space, can that reality not be manipulated or misused? (Harley, 2012). Contemporary visual approaches are often based on a relativist position that visual data are not reflection of reality, but instead have meanings that are constructed by the producers of the image and those who view it (Burles \& Thomas, 2014; Phillips \& Belanger, 2011). We as researchers 
have an ethical imperative to ensure that the ways in which we engage in research with communities honour their wisdom and expertise, and facilitate critical refection on structurally embedded experiences (Liebenberg, 2018). While our world abounds with visual images, visual data have not yet been fully accepted as a viable form of research, which can be utilized toward a serious form of data usage rather than a fringe benefit to academia (Roger, 2017).

\section{3}

\section{Research Method}

\subsection{Participants}

The research participants included 6o students who enrolled in Master of Education, an Australian transnational education program in China. Most participants were full-time teachers and administrators from higher education institutions in Helongjiang Province, Northeast China, while others were school principals and teachers. The participants ranged in age from 28 to 47 . Their working experiences ranged from five years to 25 years.

\subsection{Photovoice as an Assessment Tool}

During the intensive delivery of the subject "Training, Development and Knowledge Transfer" (ТDKT) in 2008, as part of the course requirements, the students completed a photovoice project. It consisted of four selected photographs, a photo-essay, and individual reflections. Participants were instructed to choose four photographs, provide a title/caption for each photograph, and compose a narrative describing how the photograph depicted their experiences with globalization in China. They were required to select the photographs which they have taken recently rather than downloading images from websites or using other people's photographs. The stated assignment was to provide explanations of how the selected photographs expressed his/her personal observation of impacts of globalization on a particular aspect of their lives, i.e. society, culture, education, and training.

Participants were given one week to select photographs and complete narratives. They also provided personal reflections on their experience as a photographer and their overall experience with using photovoice as an assessment. Eight groups were comprised of up to eight participants and were facilitated by me and four tutors. Group reflection pieces were also collected from each group on the last teaching day after their presentations. Students were encouraged to get below the surface description of a photographic image to describe the meaning of the photograph, display thinking deeper than surface description of phenomena to analyse the social/political context that causes the situation and produce analytical responses in their essays. 


\subsection{Photovoice as Methodology and Pedagogy}

The subject TDKT was delivered in an intensive teaching week, with five class hours per day. Students spent approximately one hour each day in class on the topic of photovoice. On the first day, I introduced photovoice as a participatory qualitative methodology, explained ethics issues and informed consent, and clarified steps and requirements for the photovoice project. They then regularly met in small groups during the week to discuss what their photographs meant to them and how the photographs reflected their experiences of globalization. I facilitated and observed their group activities.

The purpose of group work during the intensive teaching week was to provide participants with the opportunity to share their photographs and reflections with others in their group, and to generate deeper reflection and dialogue amongst participants. They engaged in dialogue with one another and the facilitators about the meaning behind each of the chosen photographs. The project used an elicitation approach that specifically called for critical reflection by focusing attention on both positive and negative impacts of globalization on their lives. This was a pivotal key to their emotional engagement and critical reflection necessary to raise critical consciousness. Participants demonstrated enthusiasm and engagement when they began to document and share their lived experiences. They took photographs of their experiences with globalization, discussed them in a group, wrote narratives to accompany selected images, and shared presentations in class on the last day.The data collected included 6o photovoice essays and 244 photographs, participants' individual reflections and group reflections, and evaluations of the course.

\subsection{Ethical Considerations}

The ethics of a photovoice project revolve around capturing a person's image and include protecting privacy and anonymity, not intruding into personal space, not placing someone in a false light (Goodhart et al., 2006). Participants were required to obtain informed consent from people shown in their selected photographs. If they were unable to obtain consent from the subjects in their photos, participants were required to blur faces or cover eyes of the subjects. Participants were promised that their identities would be known only to the researcher/teacher. I secured consent from all participants with the understanding that their confidentiality would be maintained and that all publication would remove any identifying demographic information.

To safeguard confidentiality and anonymity of the participants, each student was given a coded number (Student 1 through 6o, e.g. S1, S2.). Six selected photographs and accompanying narratives are provided in this article to illustrate key findings. The narratives were translated from Chinese into English by the researcher, an accredited translator. 


\subsection{Data Analysis}

The data process was based on grounded-theory approach in which categories are developed as they emerge from the data rather than according to performed categories based on assumptions about what might be discovered (see Amsden \& VanWynsberghe, 2005). Grounded theory is a qualitative research approach that was originally developed by Glaser and Strauss in the 1960s. The analysis involved grounded theorizing using the data to develop the emerging categories as opposed to a predetermined coded response (Caraher, Baker, \& Burns, 2004). The actual process of coding began by transferring the titles/ captions and key descriptors in each narrative onto colored sticky notes, so at I was able to move the notes and categorize data into emerging categories. The resulting piles of stick notes from each photograph and narrative were then sorted into categories that seemed to "make sense".

Initial analysis resulted in the development of 11 categories in Society, 12 categories in Culture, 7 categories in Education, and 8 categories in Training. However, these emerging categories did not exist as separate entities, because there were overlaps between the various aspects. Iterative analysis resulted in combinations of some of the categories and rejection of others. The emerging categories were then reduced to 9 key themes in society and culture, and 8 key themes in education and training. When all of these categories were pooled together, I revisited some of the data in categories to ensure that the final set of themes adequately reflected the data set as a whole. I also analyzed students' individual and collective reflections on their experiences of completing the photovoice project.

\section{$4 \quad$ Findings}

Nine key themes on impacts of globalization on society and culture include: rapid economic and financial development; deterioration of environment; consumerism and leisure culture; an increasing variety of food cultures; influence of Western architecture and sculpture; influence of Western festivals and weddings; cultural exchange, interaction, and integration; popularity of cyberculture and Western pop culture; concerns about global issues.

Eight key themes on impacts of globalization on education/training include: popularity of bilingual education and English training schools; international education and studying abroad; cross-border/transnational education; participating in activities with foreign experts or teachers; overseas visits and study tour; adapting Western ideas to practice; engaging with the international 
research and education communities; information technology in education and training.

\subsection{Selected Photographs and Narratives}

The first key theme on "rapid economic and financial development" emerged as some participants photographed fancy stores and Neon lights, streets with Neon signs of transnational companies and foreign banks, and people engaged in stock investment. For instance, a photograph captured an impressive Coca Cola advertisement board along Nanjing Road in Shanghai. The photographer (S59) explained, "Nowadays, the world economy is no longer dominated by the European nations and the USA. Developing countries like China and India are playing an increasingly important role in shaping the world economic development strategies". Another student ( $\left.\mathrm{S}_{43}\right)$ depicted a busy street in Shanghai, a commercial and financial centre in China (Figure 1).

The second key theme on "deterioration of environment" emerged as many students photographed grey skies, cities covered by smog, and streets packed

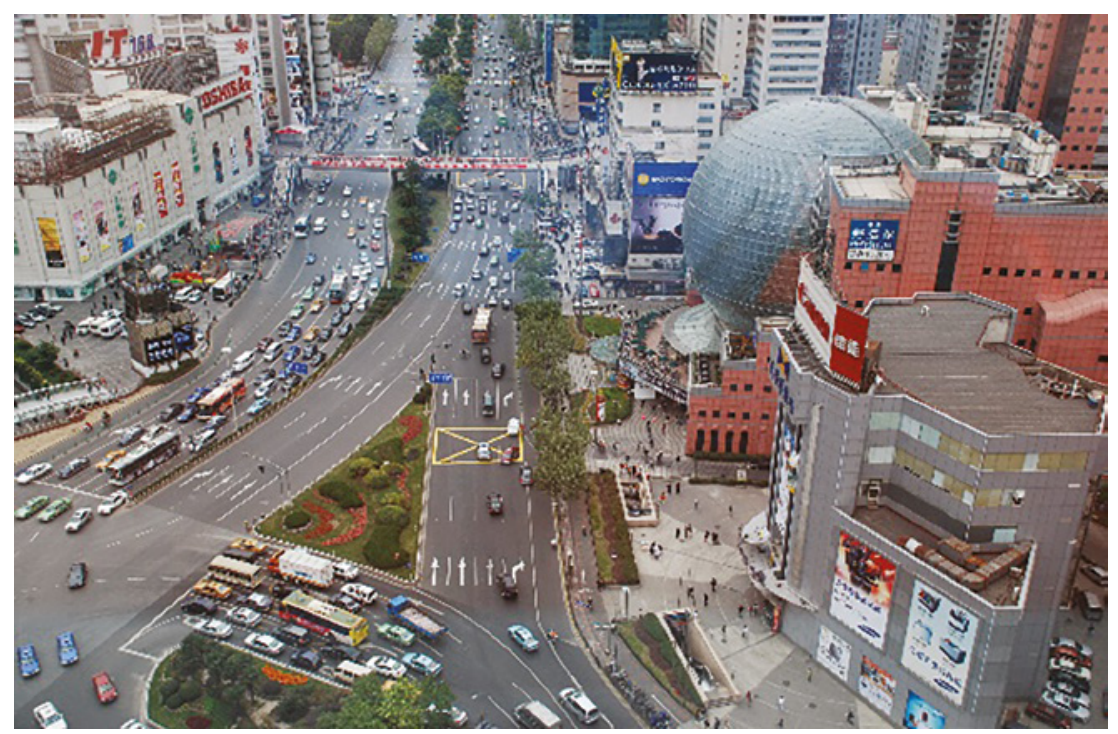

Narrative: In terms of economy, culture, and education, Shanghai closely follows the global trend. It can be seen from the photograph that many international famous brands (Canon, Toshiba, and Samsung) have an important market share in China and some foreign banks (Chartered Bank, Netherland Bank) have established their branches in Shanghai. The phenomena indicate that globalization promotes economic development and international trade across the globe. $\left(\mathrm{S}_{43}\right)$

FIGURE 1 International finance in a prosperous metropolis 


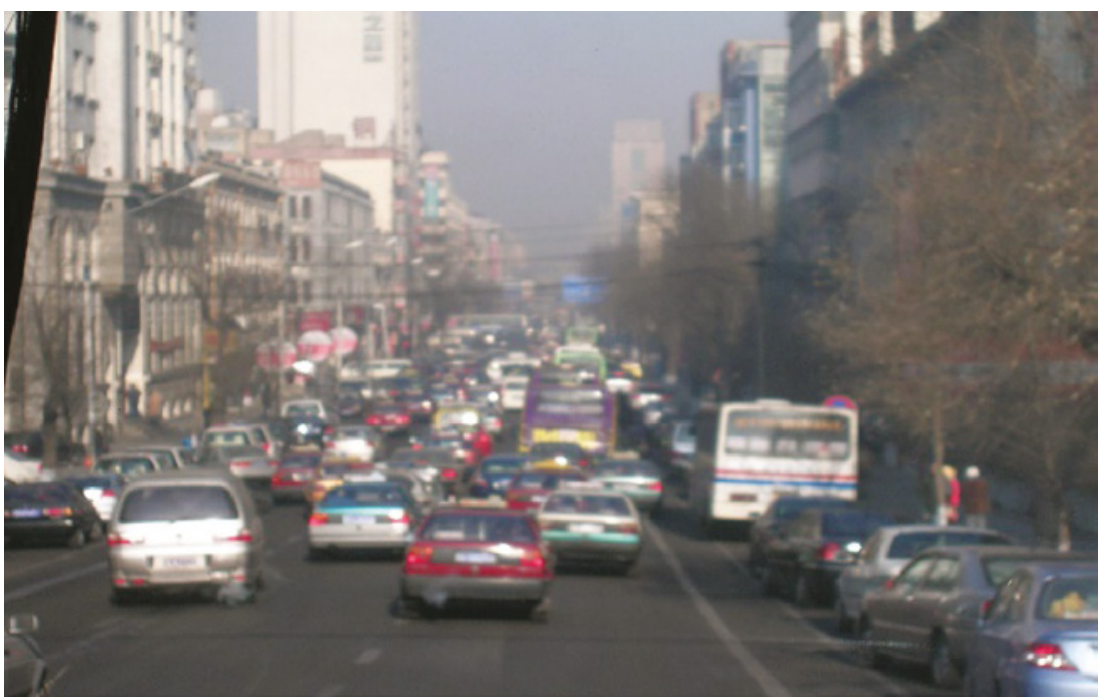

Narrative: This was not taken during the rush hours. Nor was the vehicle emission most serious during the day. However, it can be seen clearly that the city of Harbin was covered by the polluted air and smog. Globalization has a two-fold impact on environment. Globalization intensifies global environment crisis, whereas helping to promote the global environmental collaboration and management $(\mathrm{S} 25)$

FIGURE 2 Endless cars in the street: Air pollution and traffic jam

with cars. A student $\left(\mathrm{S}_{51}\right)$ took an image of a newly established shopping mall in a small town. He commented that "globalization's antenna" has even reached remote areas in China. Globalization has brought about development opportunities for China, but he lamented that China has become "the world's factory", and therefore "is facing serous environment problems, explorative use of resources, and energy crisis." Another student ( $\mathrm{S}_{25}$ ) took a photo of endless cars in a busy street to demonstrate a serious problem of air pollution and traffic jam. She argued in the narrative, "Globalization leads to an increasing number of private vehicles as well as serious air pollution in China. The negative impacts of globalization are much greater than its positive impacts. Nevertheless, globalization is an irreversible trend".

Many participants chose to show certain types of tangible, visual concerns rather than portraying topics less easily photographed. However, some students were creative and used visual metaphors in their photographs (see Figure 3). Metaphor often relies on an economy of signs and symbols. In contrast to positivist ideas of expressing data, metaphor is less about representing 


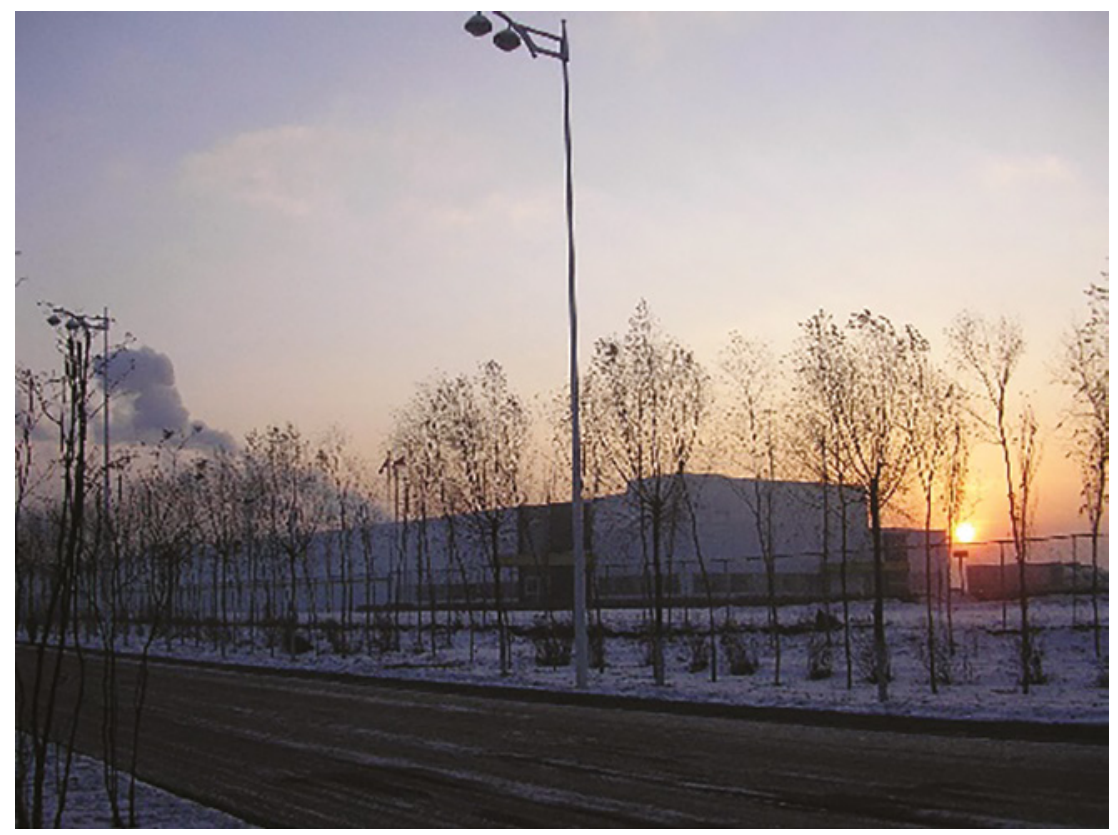

Narrative: Globalization leads to labor-intensive, resource-intensive, and polluting industries relocating to developing countries.... On the one hand, we should continue to bring in labor-intensive industries with advanced technologies, increase employment opportunities, expand exports, and complete the industrialization process. On the other hand, we should take opportunities, develop high-tech industries, refuse to let polluting industries come to China, and speed up our modernization...... (S47)

FIGURE 3 Sunrise penetrating the smog

tangible, concrete facts, and more about communicating an essence or feeling that is often outside of language (McIntosh, 2010; Switzer, 2019). For example, a student (S47) took a photograph in a new Economic Development Zone. In the narrative, he commented, "From the smog we can see that industrial development has polluted our local environment. However, we should not stop eating in fear of being choked. Sunrise penetrating the smog represents our hope and bright future."

While some students photographed exotic restaurants to illustrate "an increasing variety of food cultures", others told powerful stories about "consumerism and leisure culture". One photograph showed a Russian resort in Harbin. This resonated with others, who photographed Korean stores, NBA games in Shanghai, and Beijing Olympics National Stadium. An interesting photograph showed a bride in white wedding dress wearing a traditional Chinese red veil, 


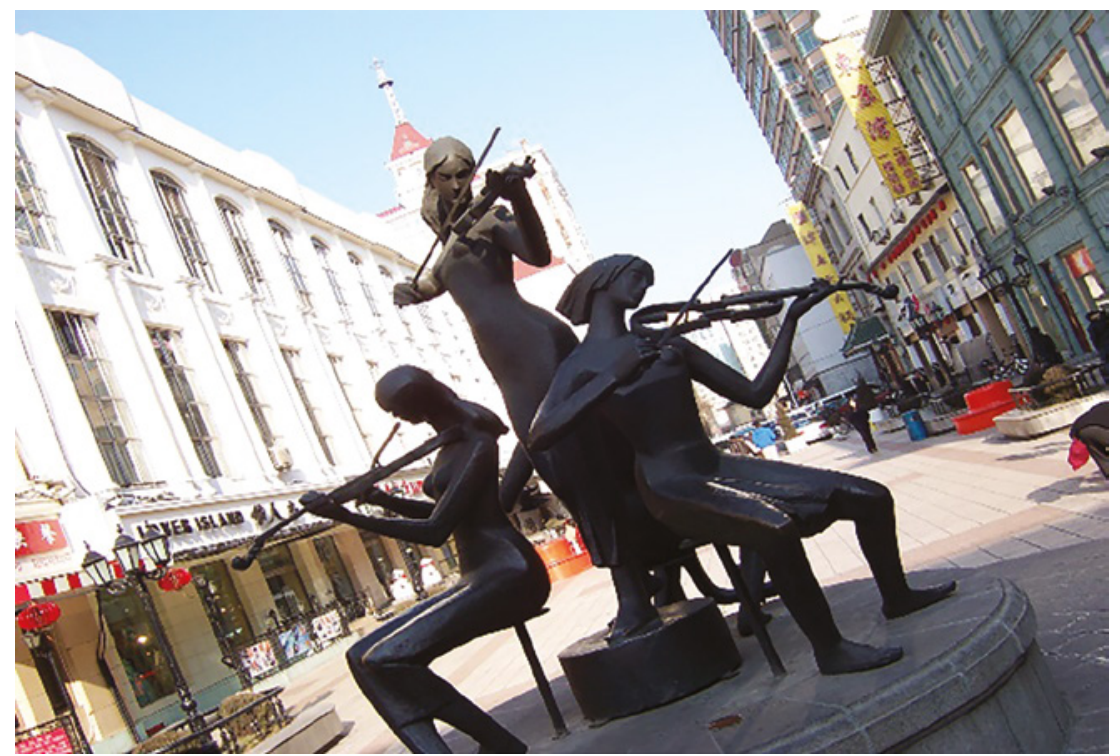

Narrative: The bronze sculpture depicts three beautiful violin players with the background of European style buildings. People may have such a feeling that they are strolling in a street of a European city.......Nowadays, it is common for us to see buildings, sculptures, and decorations with exotic features in Chinese cities. People have been gradually influenced by cultures from other countries since China opened to the outside world. In terms of food culture, western restaurants, pubs, and fast food are popular; as for leisure culture, people like Hollywood movies and KTV clubs. People celebrate New Year and Christmas in addition to traditional Chinese New Year...... (S10)

FIGURE 4 This is not in Europe

which depicted a mixture of western and Chinese weddings in a globalized context. Some were interested in the influence of Western architecture and sculptures in Chinese cities (see Figure 4). The photographer (S10) explained in the narrative, "We are happy to accept exotic cultures and now experiencing changes brought about by them while maintaining our traditional culture."

Another important theme emerged which illustrated the dynamic cultural interaction, exchange, and integration. One photograph showed several foreigners performing Beijing Opera at the stage while in another, a group of Russian young men were playing Taiji (Shadow boxing). A photograph entitled "A foreign sculpture wearing Beijing Opera Mask" struck me, and as explained by the student (S9), "Westerners also gradually accept Chinese traditional culture because they appreciate unique Chinese arts and cultural traditions". Some students were highly inventive and motivated to couple 


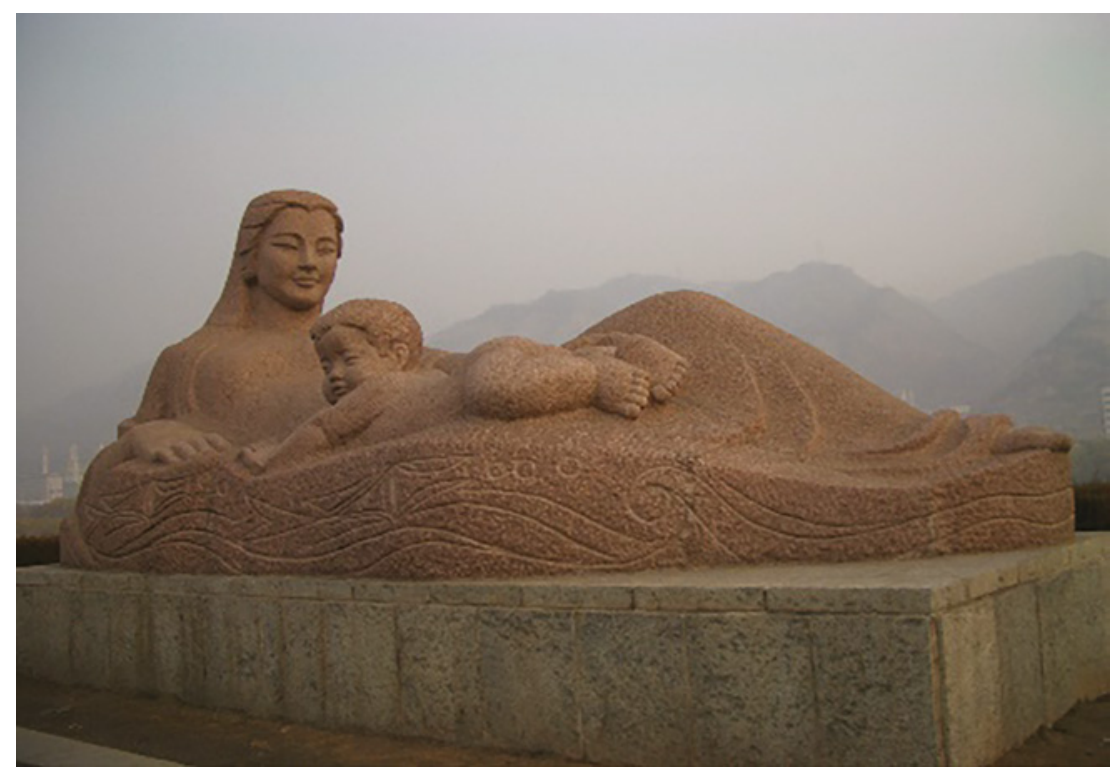

Narrative: It was my first time to visit Northwest China, the origin of Chinese culture. I was overwhelmed by the unique regional scenery and richness of Chinese culture. I appreciated inclusiveness of "Yellow River Civilization", which is like the mother shown in the photo, ready to hold everything in her arms, accept various exotic cultures, and adapt them to the Chinese context...The emergence of multiculturalism facilitates interaction and integration between different cultures. However, we won't allow one dominant culture, cultural imperialism or cultural hegemony. China is opening her arms to welcome diverse cultures and building a modern society with multi-cultural influences. $\left(\mathrm{S}_{56}\right)$

FIGURE 5 The Great Mother

visual metaphor with narrative to convey deep meanings behind the photograph (see Figure 5).

The first key theme about impact of globalization on education/training focused on "popularity of bilingual education and English training schools". Participants expressed concerns about some emerging issues in contemporary Chinese early childhood and school education. For instance, a participant (S35) photographed two Mickey Mouse cartoon figures and told a powerful story. When she collected her niece from the kindergarten, she was instantly attracted by various Disney cartoon figures posted on the walls. When she asked her niece if she liked Monkey King and Ne'za (heroes in Chinese traditional literature), the little girl was puzzled and asked who they were, because she had never heard of them. She reflected, "What is wrong with our education with children and isn't this an important issue for Chinese educators to address?" 


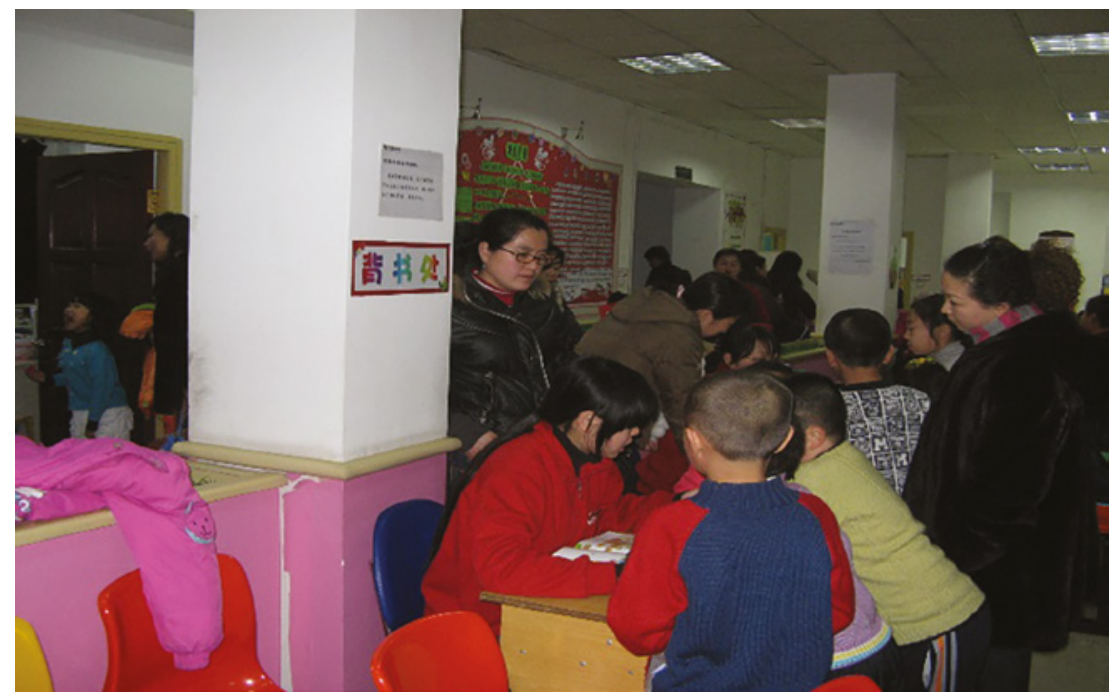

Narrative: The vision of the school is to make students complete a 12-level English course and realize the dream of achieving high level English proficiency within three years...... Besides taking a range of tests, children rushed to the teacher to recite English lessons before and after the class and during the break, and they were rewarded with prizes. Hearing children's voices up and down and seeing parents' eager faces, I was astonished and seemed to see children in ancient China reciting "Classic Books" and preparing for "the Imperial Examinations". Crazy English! When a country's children are all crazy about learning English, this is the ultimate sadness! (S29)

FIGURE 6 Young children eager to recite English lessons

Interestingly, many participants photographed various bilingual pre-schools/ kindergartens and English training schools to highlight "invasion of western education". Their photographs documented over-emphasized English language skills, and parents' craze for their children to study English at an early age in order to prepare them to be "competitive global citizens" (see Figure 6). A student (S29) took a photo of an English training school. Her son was a Year One student and attended English class twice a week in this school. She lamented, "I personally experienced Chinese people's craze for English".

Studying abroad, cross-border education, overseas visits and study tours, educational exchange opportunities were also important themes related to the impacts of globalization on Chinese education and training. As revealed by some photos and narratives, in a globalized world, education has become 
borderless. In the past, Chinese students had to go overseas to study in foreign universities. A typical comment was, "Nowadays, thanks to this transnational education program, we are able to undertake an Australian postgraduate course without crossing border. We do not have to go through complicated visa application procedure or pay for expensive tuition fees" (S14). However, many participants also expressed concerns about the dominant Western culture and cultural imperialism. Some made it clear that globalization should provide win-win situations for both developed and developing countries. Globalization is not Americanization. Nor English should be the only dominant language in the world. They called for an imperative to adopt an open and discerning attitude towards globalization and external influences from other nations.

\subsection{Reflections on Experiences with Photovoice}

Participants took photographs capturing issues in their lived, local experiences related to globalization. They engaged in reflexive dialogues about their experiences in a globalized context. The project produced an unanticipated unleashing of enthusiasm that resulted in new levels of individual and collective responsibility and participation, as clearly shown in their photographs, narratives and reflections.

Individual students and groups reflected on their learnings from completing the photovoice project and sharing their experiences. They reported photovoice to be an effective, interesting, new, and unique research method for them. They developed their observational and analytical skills. The photovoice project enhanced their critical consciousness and deepened their understandings about impacts of globalization on China. They came to understand the procedure and importance of obtaining informed consent when conducting research. In individual reflections, some participants critically examined the applicability of photovoice in their future teaching and research practices.

When a series of photographs were presented in front of me, I was actually shocked because I didn't realize that Chinese culture and education have gradually changed, and globalization would have such a great impact on China.... I did not pay much attention to this issue before. Completing the photovoice assignment makes me reflect on what to carry on as essence of our culture and what to discard in a globalized context.

Photovoice as a research method is very useful for sociology and education areas which cannot be simply measured by quantitative approaches. I would like to apply this in my teaching and research. 


\subsection{Research Implications}

The study suggests that photovoice as a participatory research methodology has educational and cultural appropriateness for Chinese students. Sifting through their recent photographs or taking photographs during the intensive teaching week triggered participants' reflections on their experiences and what they wanted to convey to others about living in a globalized world. Sharing their photographs with the group prompted deep discussions of significant issues that had not surfaced previously. The images and narratives conveyed their concerns about challenges and opportunities brought about by globalization to contemporary China. Their reflections on learnings from completing the assessment showed that photovoice can be employed as an effective participatory research approach and a creative pedagogical tool. Photovoice can serve as a unique research method vivifying participants' subjective experiences with other social phenomena.

The findings of the study showed that photovoice related learning can be emancipatory and transformative. The photovoice project developed the participants' abilities to discern the significant meanings behind the photographs and enhanced their critical reflections on both negative and positive impacts of globalization. Photovoice was a unique way to engage these participants because as educators they can personally see its benefits and decide to employ photovoice in their future teaching and research practices. Photovoice offered opportunities for them to take class information (about knowledge transfer, research methods, and critical reflections) outside of the classroom to see where and how it applies to their everyday life. Photovoice empowered them to be more aware of their surroundings. They see themselves as researchers and photographers, collecting and analyzing data and reflecting on critical issues. Photovoice enabled them to see the causes and effects of the problems brought by globalization and to start finding solutions. This process helped them to examine everyday lives from diverse perspectives, enhance their critical consciousness, and sharpen their awareness of the issues they face.

The findings revealed that photovoice as a non-conventional qualitative methodology contributed to nuanced understanding of impacts of globalization on China. Photovoice served as an alternative way of gaining input from people directly affected by globalization. The methodology offered a novel way to tap creativity of people from diverse backgrounds. When conducting interviews or questionnaire surveys, respondents are often limited by how questions are framed. Photovoice can give us a unique opportunity to learn about globalization through participants-produced information. Although the 
practical use of photovoice among students warrants further study, photovoice could be used as an alternative method to enhance understanding of critical issues. This would allow researchers to understand more fully and identify the dimensions of the dynamics involved in these issues which may not be captured through more conventional approaches.

\subsection{Limitations of the Study}

Despite the benefits of photovoice as an effective methodology and pedagogical tool, several study limitations are acknowledged. A limitation was the substantial modification to the standard photovoice protocol due to time constraints. Variation in the photovoice project did not allow for individual interviews or exhibit of the participants' images and narratives at public forums. Although the participants experienced a sense of achievement with the completion of their projects, most students did not develop participatory social actions. Due to limited time for group sharing during the intensive teaching week, only representatives from each of the eight groups presented their photographs and narratives. The group reflection pieces submitted by students on the last teaching day did not generate enough data for me to perform indepth analyses of their collective reflections and responses to social actions.

\subsection{Directions for Future Research}

Future photovoice projects could allow a much longer period with more time allocated to participants for sharing the images, analysing the data, and deciding social actions. The photograph exhibits could be held to disseminate results and inform stakeholders and policy makers. Additionally, most participants valued the experience and felt empowered, whereas a few did not seem to understand the rigor of this research method. I noticed that most students were excited to share their ideas and examine the meanings behind their photographs, while some continued to figure out what the teacher wanted as the "right answer". A few students chose photographs which were similar to what I showed as samples in class to demonstrate the photovoice process. There issues were considered and creativity and empowerment were encouraged among participants in the subsequent photovoice projects which I conducted in the following years.

This study captures the efficacy of photovoice and reveals that educators can adopt and adapt photovoice methodology for their own use. They can design 
their photovoice projects for both research and pedagogical purposes. The findings show that learner-generated photography was central to students' experiences of critical reflection, creation and transfer of knowledge, and critical awareness of change making. Most participants in this study found photovoice engaging and interesting. The enthusiasm generated by sharing images positively impacted meaningful discussions going on in class. Photovoice was used to honour everyone's perspective and value individual and collective voices. It acted as a clear lens to link research concepts to the lived, local experience of participants.

The findings show that the photovoice project had positive implications for participants. The photovoice approach provided them with opportunities to actively engage with their social environment through photography, to participate in critical analysis and respond to the issues they identify as important. Involving people in research about their lived experience may increase relevancy of research to real life situations. Research participants have a diversity of experience and can bring considerable vitality to organizations and events with which they are involved and the wider social and cultural contexts. This study also highlights the usefulness of context-specific, transferable, and innovative pedagogical tool designed to promote learners' critical consciousness and empowerment.

Despite the promise of photovoice as a participatory methodology and empowerment tool to engage participants and reach out policy makers for social action, photovoice is not a panacea. It is not immune from critiques or limitations. Qualitative research in the digital era is faced with obstacles and opportunities. We are reaching the point where virtually everyone has a smart phone, and wireless connectedness and respective apps allow us to envision possibilities for visual research (Palys \& Atchison, 2012). Wang and Burris (1997) explicitly state that the photovoice technique should be "creatively and flexibly adapted to the needs of its users" (p. 383). There are rising issues which have considerable impact for contemporary photovoice researchers. We need to make our own decisions about how to address various challenges based on our own contexts and specific experiences and considerations. I would argue the rigor of photovoice research does not necessarily mean a rigid process or a one-size-fits-all prescription. In ever changing social settings, appropriate variations and deliberate design in consideration of complexity, fluidity and diversity of factors and local needs can lead to sophisticated and context-specific design and implementation of photovoice projects. The promise of photovoice as a powerful visual research methodology and pedagogy lies in the rigor, trustworthiness and adaptation of project design and process. There are new possibilities for future visual research in the digital age. 


\section{Acknowledgement}

An earlier version of this article was presented at 2009 Australian Association for Research in Education (AARE) International Educational Research Conference.

\section{References}

Amsden, J., \& VanWynsberghe, R. (2005). Community mapping as a research tool with youth. Action Research, 3(4), 357-381.

Baker, T. A., \& Wang, C. C. (2006). Photovoice: Use of a participatory action research method to explore the chronic pain experience in older adults. Qualitative Health Research, $16(10)$, 1405-1413.

Bender, D. E., Harbour, C., Thorp, J., \& Morris, P. (2001). Tell me what you mean by "si": Perceptions of quality of prenatal care among immigrant Latina women. Qualitative Health Research, $11(6), 780-794$.

Bennett, B., Maar, M., Manitowabi, D., Moeke-Pickering, T., Trudeau-Peltier, D., \& Trudeau, S. (2019). The Gaataa'aabing visual research method: A culturally safe Anishinaabek transformation of photovoice. International Journal of Qualitative Methods, 18. https://doi:10.1177/1609406919851635.

Berman, H., Ford-Bilboe, M., Moutrey, B., \& Cekic, S. (2001). Portraits of pain and promise: A photographic study of Bosnian youth. Canadian Journal of Nursing Research, 32, 21-41.

Brinton Lykes, M. (1999). Telling stories - rethreading lives: community education, women's development and social change among Maya Ixil. International Journal of leadership in Education, 2, 207-227.

Burles, M., \& Thomas, R. (2014). "I just don't think there's any other image that tells the story like [this] picture does": Researcher and participant reflections on the use of participant-employed photography in social research. International Journal of Qualitative Methods, 13(1), 185-205. https://doi:10.1177/160940691401300107.

Capous-Desyllas, M., \& Bromfield, N. F. (2018). Using an arts-informed eclectic approach to photovoice data analysis. International Journal of Qualitative Methods, 17(1). https://doi:10.1177/1609406917752189.

Caraher, M., Baker, H., \& Burns, M. (2004). Childern's views of cooking and food preparation. Bristish Food Journal, 106(4), 255-273.

Carnahan, C. R. (2006). Photovoice: Engaging children with Autism and their teachers. Teaching Exceptional Children, 39(2), 44-50.

Chio, V. C. M., \& Fandit, P. M. (2007). Photovoice in the diversity classroom: Engagement, voice and the "Eye/I" of the camera. Journal of Managment Education, 37(4), 484-504. 
Ciolan, L., \& Manasia, L. (2017). Reframing photovoice to boost its potential for learning research. International Journal of Qualitative Methods, 16(1). https://doi:10 $.1177 / 1609406917702909$.

Collier, J. (1979). Visual anthropology. In J. Wagner (Ed.), Images of information (pp. 161-169). SAGE.

Collier, J., \& Collier, M. (1986). Visual anthropology: Photography as a research method. University of New Mexico.

Dixon, M., \& Hadjialexiou, M. (2005). Photovoice: Promising practice in engaging young people who are homeless. Youth Studies Australia, 24(2), 52-56.

Fournier, B., Mill, J., Kipp, W., \& Walusimbi, M. (2007). Discovering voice: A participatory action research study with nurses in Uganda. International Journal of Qualitative Mothods, 6(2). 1-19.

Freire, P. (1970). Pedagogy of the oppressed. Continuum.

Freire, P. (1973). Education for critical consciousness. Continuum.

Gallo, M. L. (2002). Picture this: immigrant workers use photography for communication and change. Journal of Workplace Learning, 14(2), 49-57.

Goodhart, F. W., Hsu, J., Baek, J. H., Coleman, A. L., Maresca, F., \& Miller, M. B. (2006). A view through a different lens: Photovoice as a tool for student advocacy.Journal of American College Health, 55, 53-56.

Gosselink, C. A., \& Myllykangas, S. A. (2007). The leisure experiences of older U.S. women living with HIV/AIDS. Health Care for Women International, 28, $3^{-20 .}$

Gubrium, A., \& Harper, K. (2013). Participatory visual and digital methods. Left Coast Press.

Hannes, K., \& Parylo, O. (2014). Let's play it safe: Ethical considerations from participants in a photovoice research project. International Journal of Qualitative Methods, 13(1). https://doi:10.1177/160940691401300112.

Harley, A. (2012). Picturing reality: Power, ethics, and politics in using photovoice. International Journal of Qualitative Methods, 11(4), 320-339. https://doi:10.1177/ 160940691201100402.

Harper, K. (2019). Essentials of photovoice in participatory visual research. Routledge.

Harrison, B. (2002). Photographic visions and narrative inquiry. Narrative Inquiry, 12(1), $87-111$.

Hernandez, K., Shabazian, A. N., \& McGrath, C. (2014). Photovoice as a pedagogical tool: Examining the parallel learning processes of college students and preschool children through service learning. Creative Education, 5, 1947-1957.

Killion, C. M., \& Wang, C. C. (1999). Linking African American mothers acrss life stage and station through photovoice. Journal of Health Care for the Poor and Underserved, $11(3), 310-325$. 
Komaie, G., Gilbert, K. L., Arroyo, C., \& Goodman, M. S. (2018). Photovoice as a pedagogical tool to increase research literacy among community members. Pedagogy in Health Promotion, 4(2), 108-114. https://doi:10.1177/2373379917715652.

Kroeger, S., Burton, C., Comarata, A., Combs, C., Hamm, C., Hopkins, R., \& et al. (2004). Student voice and critical reflection: Helping students at risk. Teaching Exceptional Children, 36(3), 50-57.

Latz, A. O. (2017). PhotoVoice research in education and beyond: A practical guide from theory to exhibition. Routledge.

Latz, A. O., Phelps-Ward, R., Royer, D., \& Peters, T. (2016). Photovoice as methodology, pedagogy, and partnership-building tool: A graduate and community college student collaboration. Journal of Public Scholarship in Higher Education, 6, 124-142.

LeClerc, C. M., Wells, D. L., Craig, D., \& Wilson, J. L. (2002). Fallinig short of the mark: Tales of life after hospital discharge. Clinical Nursing Research, 11(3), 242-263.

Liebenberg, L. (2018). Thinking critically about photovoice: Achieving empowerment and social change. International Journal of Qualitative Methods, 17(1). https:// doi:10.1177/1609406918757631.

McIntosh, P. (2010). The puzzle of metaphor and voice in arts-based social research. International Journal of Social Research Methodology, 13, 157-169. https:// doi:10.1080/13645570902969357.

McIntyre, A. (2003). Through the eyes of women: Photovoice and participatory research as tools for re-imagining place. Gender, Place, \& Culture, 1o(1), 47-66.

Mueller, C. (2006). Creating a joint partnership: including Qallunaat teacher voices within Nunavik eduction policy. International Journal of Inclusive Education, $10(4-5), 429-447$.

Nowell, R. L., Berkowitz, S. L., Deacon, Z., \& Foster-Fisherman, P. (2006). Revealing the cues within community places: stories of identity, history, and possibility. American Journal of Community Psychology, 37(1-2), 29-46.

Nykiforuk, C. I. J., Vallianatos, H., \& Nieuwendyk, L. M. (2011). Photovoice as a method for revealing community perceptions of the built and social environment. International Journal of Qualitative Methods, 10(2), 103-124. https://doi:10.1177/160940 691101000201.

Oliffe, J., \& Bottorff, J. (2007). Further than the eye can see? Photo elicitation and research with men. Qualitative Health Research, 17, 850-858.

Pain, H. (2012). A literature review to evaluate the choice and use of visual methods. International Journal of Qualitative Methods, 11(4), 303-319. https://doi:10.1177/ 160940691201100401.

Palys, T., \& Atchison, C. (2012). Qualitative research in the digital era: Obstacles and opportunities. International Journal of Qualitative Methods, 11(4), 352-367. https:// doi:10.1177/160940691201100404. 
Phillips, C., \& Belanger, A. (2011). Feeling the cut: Exploring the use of photography in social work education. Qualitative Social Work, 10(1), 86-105. https://doi:110.1177/ 1473325010361999 .

Roger, K. (2017). The fringe value of visual data in research: How behind is academia? International Journal of Qualitative Methods, 16(1). https://doi:10.1177/160940 6917736668.

Rose, G. (2014). On the relation between 'visual research methods' and contemporary visual culture. The Sociological Review, 62(1), 24-46. https://doi:10.1111/1467-954X .12109 .

Ruby, J. (2000). Picturing culture: Explorations of film and anthropology. University of Chicago Press.

Simmonds, S., Roux, C., \& Avest, I. T. (2015). Blurring the boundaries between photovoice and narrative inquiry: A narrative-photovoice methodology for gender-based research. International Journal of Qualitative Methods, 14(3), 33-49. https:// doi:10.1177/160940691501400303.

Strack, R., \& Magill, C. (2004). Engaging youth through Photovoice. Jouranl of Health Promotion Practice, 5(1), 49-58.

Switzer, S. (2019). Working with photo installation and metaphor: Re-visioning photovoice research. International Journal of Qualitative Methods, 18. https://doi:10.1177/ 1609406919872395 .

Thomas, R., Gifford, W., Poudrier, J., Hamilton, R., Brooks, C., Scott, T., ... Hammond, C. (2015). First Nations, Inuit, and Métis women's experiences of cancer survivorship: Protocol for the National Picture Project. International Journal of Qualitative Methods, 14(1), 97-120. https://doi:10.1177/160940691501400109.

Wagner, J. (1979). Images of Information. Sage.

Wallerstein, N., \& Bernstein, E. (1988). Empowerment education: Freire's ideas adapted to health education. Health Education Quarterly, 15(4), 379-394.

Wang, C. C. (1999). Photovoice: A participatory action research strategy applied to women's health. Journal of Women's Health, 8(2), 185-192.

Wang, C. C. (2003). Using Photovoice as a participatory assessment and issue selection tool: A case study with the homeless in Ann Arbor. In M. Minkler \& N. Wallerstein (Eds.), Community-based participatory research for health (pp. 179-196). JosseyBass.

Wang, C. C., \& Burris, M. A. (1994). Empowerment through photo novella: Portraits of participation Health Education Quarterly, 21, 171-186.

Wang, C. C., \& Burris, M. A. (1997). Photovoice: Concept, methodology, and use for participatory needs assessment. Health Education and Behavior, 24(3), 369-387.

Wang, C. C., Cash, J., \& Powers, L. S. (2000). Who knows the street as well as the homeless?: Promoting personal and community action through photovoice. Health Promotion Practice, $1(1), 81-89$. 
Wang, C. C., Morrel-Samuels, S., Hutchison, P., Bell, L., \& Pestronk, R. M. (2004). Flint photovoice: Community-building among youth, adults, and policy makers. American Journal of Public Health, 94(6), 911-913.

Wang, C. C., \& Pies, C. A. (2004). Family, maternal, and child health through photovoice. Maternal and Child Health Journal, 8(2), 95-102.

Wang, C. C., \& Redwood-Jones, Y. A. (2001). Photovoice ethics: Perspectives from flint photovoice. Health Education and Behavior, 28(5), 560-572.

Wang, C. C., Wu, K. Y., Zhan, W. T., \& Carovano, K. (1998). Photovoice as a participatory health promotion strategy. Health Promotion International, 13(1), 75-86.

Wang, C. C., Yuan, Y. L., \& Feng, M. L. (1996). Photovoice as a tool for participatory education: The community's view of process and impact. Journal of Contemporary Health, 4, 47-49.

Warren, S. (2005). Photography and voice in critical qualitative management research Accounting, Auditing \& Accountability Journal, 18(6), 861-882.

Wilson, N., Dasho, S., Martin, A. C., Wallerstein, N., Wang, C. C., \& Minkler, M. (2007). Engaging young adolescents in social action through photovoice Journal of Early Adolescence, 27(2), 241-261. 